\title{
Ketepatan dan Kecukupan Profilaksis Venous Thromboembolism berdasar Pedoman American College of Chest Physicians di Ruang Rawat Intensif Rumah Sakit DR. Hasan Sadikin Bandung
}

\author{
Tirto Hartono, Ezra Oktaliansah, Ardi Zulfariansyah \\ Departemen Anestesiologi dan Terapi Intensif \\ Fakultas Kedokteran Universitas Padjadjaran/RSUP Dr. Hasan Sadikin Bandung
}

\begin{abstract}
Abstrak
Pasien sakit kritis adalah pasien dengan kondisi mengancam nyawa yang membutuhkan penanganan khusus di ruang rawat intensif (intensive care unit; ICU). Hampir semua pasien kritis yang dirawat di ICU memiliki beberapa faktor risiko yang meningkatkan venous thromboembolism (VTE). Venous thromboembolism merupakan komplikasi yang tersembunyi pada pasien sakit kritis yang dapat meningkatkan angka morbiditas dan mortalitas. Venous thromboembolism dapat dicegah dengan tromboprofilaksis yang sesuai dan adekuat. Pedoman pencegahan VTE dikembangkan dalam beberapa dekade salah satunya oleh American College of Chest Physicians (ACCP). Tujuan penelitian ini mengetahui kepatuhan berdasar ketepatan dan kecukupan pemberian tromboprofilaksis terhadap pedoman ACCP. Penelitian deskiripsi observasional retrospektif dilakukan pada Oktober-Desember 2018 terhadap 284 pasien yang dirawat di Unit Perawatan Intensif Rumah Sakit Dr. Hasan Sadikin Bandung periode Januari-Desember 2016. Secara keseluruhan proporsi pasien di ICU yang mendapatkan tromboprofilaksis, yaitu 36,1\%. Angka kepatuhan pemberian profilaksis VTE di ICU berdasar pedoman ACCP adalah 21,5\%. Pemberian profilaksis VTE yang tidak adekuat terdapat pada $12,4 \%$ pasien, sedangkan pemberian profilaksis yang tidak sesuai terdapat pada $2,2 \%$ pasien. Simpulan, kepatuhan pemberian tromboprofilaksis terhadap pedoman yang diterbitkan ACCP masih rendah.
\end{abstract}

Kata kunci: American College of Chest Physicians, kepatuhan, tromboprofilaksis, venous thromboembolism

\section{Adequacy and Accuracy of Venous Thromboembolism Prophylaxis based on American College of Chest Physicians Guideline at Intensive Care Unit of Dr. Hasan Sadikin General Hospital Bandung}

\begin{abstract}
Critically ill patients are patients with life-threatening conditions that require special treatment in the intensive care unit. Almost all critical patients admitted to the ICU have several risk factors that increase the occurrence of Venous thromboembolism (VTE). Venous thromboembolism is a hidden complication in critically ill patients that can increase morbidity and mortality. Venous thromboembolism can be prevented with appropriate and adequate thromboprophylaxis. Several thromboprophylaxis guidelines have been developed during the last decades, including the American College of Chest Physicians (ACCP) guideline. The purpose of this study was to determine the compliance to ACCP guideline by measuring the the accuracy and adequacy of thromboprophylaxis. This retrospective observational descriptive study was conducted from October-December 2018 on 284 patients treated in the Intensive Care Unit of Dr. Hasan Sadikin General Hospital Bandung. The overall proportion of patients in ICU who received thromboprophylaxis was $36.1 \%$. The compliance rate of VTE prophylaxis in ICU based on ACCP guideline was $21.5 \%$. Inadequate VTE prophylaxis was seen in $12.4 \%$ of patients while inappropriate prophylaxis was identified in $2.2 \%$ of patients. Hence, the compliance to standards on thromboprophylaxis based on the ACCP guideline is still low in this hospital.
\end{abstract}

Key words: Accuracy, American College of Chest Physicians, sufficiency, thromboprophylaxis, venous thromboembolism

Korespondensi: Tirto Hartono, dr, Departemen Anestesiologi dan Terapi Intensif Fakultas Kedokteran Universitas Padjadjaran/RSUP Dr. Hasan Sadikin Bandung, Jl. Pasteur No. 38 Bandung 40161, Tlpn (022) 203-8285, Email tirto.81@gmail.com 


\section{Pendahuluan}

Pasien sakit kritis adalah pasien dengan kondisi yang sangat mengancam nyawa yang membutuhkan penanganan khusus di ruang rawat intensif (intensive care unit; ICU). ${ }^{1,2}$ Imobilisasi dan inaktivitas pada pasien sakit kritis, disfungsi endotel vaskular, hiperkoagulabilitas, dan pengaruh penyakit yang mendasari berperan dalam pembentukan gumpalan darah atau clot dengan merusak keseimbangan sistem koagulasi dan fibrinolisis sehingga menyebabkan tromboemboli vena (venous thromboembolism; VTE). ${ }^{2-4}$

Venous thromboembolism atau VTE dengan manifestasi klinisnya trombosis vena dalam (DVT) dan emboli paru (PE) merupakan komplikasi yang sering dijumpai pada pasienpasien yang dirawat di ruang ICU. ${ }^{5}$ Venous thromboembolism terjadi sekitar 250.000 kasus per tahun di Amerika (1992). ${ }^{6}$

Penelitian pada autopsi pasien sakit kritis yang meninggal mengungkapkan bahwa emboli paru terjadi pada $27 \%$ pasien sakit kritis dan sebagian besar kasus ini tidak ada kecurigaan klinis trombosis vena atau emboli paru sebelum kematian. Penelitian telah menunjukkan bahwa kejadian VTE di rumah sakit dapat dicegah dengan memberikan profilaksis yang tepat. ${ }^{7}$ Venous thromboembolism itu dapat berakibat fatal, oleh karena itu pencegahan adalah cara terbaik untuk membatasi konsekuensi yang merugikan dari kondisi ini. ${ }^{2}$

Dalam dekade terakhir banyak pedoman telah dikembangkan untuk meningkatkan kesesuaian dan kualitas pelayanan kesehatan terhadap kelompok pasien yang berbeda (misalnya, kardiologi, onkologi, dan neurologi) dalam berbagai aspek perawatan (misalnya, pencegahan, diagnosis, dan pengobatan). ${ }^{3}$

The American College of Chest Physicians (ACCP) menerbitkan pedoman Prevention of Venous Thromboembolism: American College of Chest Physicians Evidence-Based Clinical Practice Guidelines dan merekomendasikan penggunaan obat-obatan profilaksis VTE pada pasien medis yang dirawat di rumah sakit dengan risiko VTE. Obat yang digunakan untuk pencegahan VTE adalah golongan antikoagulan, antitrombosit dan trombolitik, dan juga obat untuk mengatasi perdarahan termasuk hemostatik. ${ }^{6}$

Survei cross-sectional yang menilai kepatuhan terhadap pedoman profilaksis VTE yang diterbitkan oleh ACCP terhadap 32 negara di 5 benua menunjukkan variasi kepatuhan terhadap pedoman antara 0,2 sampai 92\% (rerata 59\%) untuk pasien bedah dan 3\% sampai 70\% (rerata 40\%) untuk pasien medis. ${ }^{3}$ Penelitian yang dilakukan di Arab Saudi menyatakan bahwa dari 178 pasien rawat inap hanya $44,1 \%$ dari pasien bedah dan $21,7 \%$ dari pasien medikal yang menerima profilaksis VTE $(\mathrm{p}<0,01)$ dengan kasus kematian sebesar 3\% untuk pasien yang menerima obat profilaksis VTE dan 31\% bagi pasien yang tidak menerima profilaksis VTE $(\mathrm{p}<0,0001){ }^{8}$

Keadaan tersebut jelas menunjukkan pelaksanaan pedoman profilaksis VTE yang kurang optimal. Meningkatkan pemberian profilaksis VTE itu telah menjadi strategi penting rumah sakit untuk meningkatkan keselamatan pasien. Pengetahuan tentang pedoman profilaksis VTE sangat penting untuk pelaksanaan pemberian profilaksis VTE yang tepat. ${ }^{9}$

Sampai dengan saat ini belum terdapat penelitian mengenai ketepatan dan kecukupan pemberian tromboprofilaksis pada pasien yang dirawat di ICU rumah sakit Dr. Hasan Sadikin terhadap pedoman profilaksis yang diterbitkan oleh ACCP. Penelitian ini bertujuan mengetahui ketepatan serta kecukupan profilaksis VTE di ruang rawat intensif Rumah Sakit Dr. Hasan Sadikin Bandung periode Januari-Desember 2016 berdasar pedoman ACCP.

\section{Subjek dan Metode}

Penelitian ini dilakukan secara deskriptif observasional retrospektif. Objek penelitian adalah data rekam medis pasien yang dirawat di ICU rumah sakit Dr. Hasan Sadikin Bandung yang memenuhi kriteria inklusi dan tidak termasuk kriteria eksklusi. Kriteria inklusi 
penelitian ini adalah data rekam medis pasien yang dirawat di ICU Rumah Sakit Dr. Hasan Sadikin Bandung periode Januari-Desember 2016. Kriteria eksklusi meliputi data rekam medis pasien yang telah terdiagnosis VTE sebelumnya. Kriteria pengeluaran meliputi data rekam medis dengan pencatatan atau dokumen yang tidak lengkap.

Penelitian ini dilakukan di Rumah Sakit Dr. Hasan Sadikin Bandung pada bulan Agustus sampai November 2018. Pengambilan sampel penelitian ini dilakukan setelah mendapatkan persetujuan (ethical clearance) dari Komite Etik Penelitian Kesehatan FK Unpad/Rumah Sakit Dr. Hasan Sadikin Bandung NO: LB.04.01/ A05/EC/191/X/2018.

Subjek penelitian meliputi seluruh data rekam medis pasien yang dirawat di ruang ICU RSUP Dr. Hasan Sadikin Bandung periode Januari-Desember 2016. Data pemakaian profilaksis VTE pada pasien yang dirawat di ICU RSUP Dr. Hasan Sadikin Bandung dicatat dan dikelompokan berdasar usia, jenis kelamin, diagnosis, faktor risiko, jenis operasi, jenis profilaksis VTE, waktu pemberian profilaksis VTE, lama pemberian profilaksis VTE, waktu penghentian profilaksis VTE. Data tersebut dihitung persentase penggunaan profilasis VTE yang sesuai dan adekuat berdasar pedoman yang diterbitkan oleh ACCP.

\section{Hasil}

Sebanyak 284 data rekam medik pasien yang menjalani perawatan di ICU periode JanuariDesember 2016 memenuhi kriteria inklusi dan tidak termasuk kriteria eksklusi maupun kriteria pengeluaran. Data karakteristik umum pasien berdasar atas usia dan jenis kelamin didapatkan kelompok usia terbanyak adalah kelompok usia lansia awal dan lansia akhir $(21,8 \%)$. Jenis kelamin laki-laki lebih banyak, yaitu $51,6 \%$. Jenis penyakit terbanyak yang dirawat adalah pasien bedah umum $(34,9 \%$; Tabel 1).

Pasien yang menjalani perawatan di ICU sebagian besar mempunyai risiko tinggi terjadi VTE, yaitu 79,9\%, sedangkan 16,6\% mempunyai risiko sedang, dan $3,5 \%$ risiko rendah. Hampir semua pasien kritis yang dirawat di ICU memiliki beberapa faktor risiko yang meningkatkan terjadi VTE. ${ }^{6}$ Penelitian ini menemukan pasien yang mempunyai indikasi pemberian profilaksis VTE sebesar 96,5\% (Tabel 2).

Penelitian ini menemukan pasien yang menerima profilaksis VTE hanya sebanyak $36,1 \%$ dari seluruh pasien yang mempunyai indikasi diberikan profilaksis VTE. Pasien yang diberikan profilaksis VTE paling banyak pada pasien nonbedah, yaitu 59,9\% (Tabel 3).

Tabel 1 Karateristik Umum Pasien

\begin{tabular}{|c|c|c|c|c|c|c|c|c|c|c|}
\hline Karakteritik & Nonbedah & Ortho & BU & Obg & Uro & TR & Sci & BS & $\mathbf{n}$ & $\%$ \\
\hline \multicolumn{11}{|l|}{ Usia (tahun) } \\
\hline $11-25$ & 2 & 7 & 8 & 9 & 0 & 4 & 0 & 9 & 39 & 13,7 \\
\hline $26-35$ & 1 & 3 & 9 & 8 & 0 & 6 & 0 & 10 & 37 & 13 \\
\hline $36-45$ & 7 & 1 & 15 & 12 & 0 & 4 & 0 & 7 & 47 & 16,5 \\
\hline $46-55$ & 13 & 2 & 24 & 6 & 1 & 2 & 1 & 14 & 62 & 21,8 \\
\hline $56-64$ & 21 & 2 & 28 & 1 & 1 & 1 & 0 & 7 & 62 & 21,8 \\
\hline$\geq 65$ & 13 & 1 & 15 & 0 & 0 & 1 & 1 & 7 & 37 & 13,2 \\
\hline \multicolumn{11}{|l|}{ Jenis kelamin } \\
\hline Laki-laki & 30 & 8 & 66 & 0 & 0 & 17 & 0 & 26 & 146 & 51,6 \\
\hline Perempuan & 27 & 8 & 33 & 36 & 2 & 1 & 2 & 28 & 137 & 48,4 \\
\hline
\end{tabular}

Keterangan: untuk data kategorik disajikan dengan jumlah/frekuensi dan persentase Ortho: ortopedi, BU: bedah umum, obg: obgin, uro: urologi, tr: trauma, sci: spinal cord injury, bs: bedah saraf 
Tabel 2 Karakteristik berdasar Faktor Risiko VTE

\begin{tabular}{lccc}
\hline \multicolumn{1}{c}{ Level Risiko } & n (\%) & $\begin{array}{c}\text { Indikasi Profilaksis } \\
\mathbf{n ~ ( \% )}\end{array}$ & $\begin{array}{c}\text { Tidak Indikasi profilaksis } \\
\mathbf{n ~ ( \% )}\end{array}$ \\
\hline Rendah & $10(3,5)$ & $0(0)$ & $10(3,5)$ \\
Sedang & $47(16,6)$ & $47(16,6)$ & $0(0)$ \\
Tinggi & $227(79,9)$ & $227(79,9)$ & $0(0)$ \\
Total & $284(100)$ & $274(96,5)$ & $10(3,5)$ \\
\hline
\end{tabular}

Keterangan: untuk data kategorik disajikan dengan jumlah dan persentase

Pada penelitian ini ditemukan pemberian profilaksis tepat dan adekuat sebesar $21,5 \%$, pemberian profilaksis yang tidak sesuai $2,2 \%$, pemberian profilaksis yang tidak adekuat $12,4 \%$, sedangkan $63,9 \%$ tidak diberikan profilaksis VTE. Sebanyak $54,4 \%$ pasien nonbedah menerima pedoman profilaksis VTE yang sesuai dan adekuat. Pasien bedah saraf memiliki tingkat kepatuhan yang paling rendah, yaitu 1,9\% (Tabel 4).

Pemberian profilaksis VTE yang tidak sesuai adalah pemberian jenis profilaksis VTE tidak sesuai dengan faktor risiko sesuai pedoman ACCP sebanyak 2,2\% (Tabel 5).

Penyebab pemberian profilaksis VTE yang tidak adekuat dinilai dari beberapa hal meliputi awal pemberian, akhir pemberian, lama pemberian, dan juga dosis pemberian. Pemberian profilaksis VTE yang tidak adekuat dikarenakan dosis yang diberikan tidak sesuai dengan pedoman, yaitu $47,1 \%$ dan mulai pemberian yang terlambat, yaitu $52,9 \%$ (Tabel $6)$.

\section{Pembahasan}

Venous thromboembolism (VTE) sering terjadi pada pasien kritis. Pasien yang dirawat di ruang perawatan intensif terdapat lebih dari satu faktor risiko yang meningkatkan angka kejadian VTE. Dalam penelitian pasien bedah di Amerika, proporsi pemberian profilaksis VTE pada pasien kritis di berbagai spesialis bervariasi dari 38\% sampai $94 \%$ bergantung pada prosedur bedah. Beberapa dekade terakhir dikembangkan beberapa pedoman untuk pencegahan VTE salah satunya adalah ACCP. ${ }^{10-12}$

Tabel 3 Karakteristik Indikasi dan Kontraindikasi Profilaksis VTE

\begin{tabular}{lcccccc}
\hline \multirow{2}{*}{ Klasifikasi pasien } & \multicolumn{3}{c}{ Indikasi } & \multicolumn{3}{c}{ Tidak Indikasi } \\
\cline { 2 - 6 } & $\mathbf{n}$ & $\begin{array}{c}\text { Profilaksis (+) } \\
\text { n (\%) }\end{array}$ & $\begin{array}{c}\text { Profilaksis (-) } \\
\text { n (\%) }\end{array}$ & $\mathbf{n}$ & $\begin{array}{c}\text { Profilaksis (+) } \\
\text { n (\%) }\end{array}$ & $\begin{array}{c}\text { Profilaksis (-) } \\
\text { n (\%) }\end{array}$ \\
\hline Pasien nonbedah & 57 & $34(59,9)$ & $23(40,1)$ & 0 & 0 & 0 \\
Bedah ortopedi & 6 & $3(50)$ & $3(50)$ & 10 & 0 & $10(100)$ \\
Bedah umum & 99 & $45(45,5)$ & $54(54,6)$ & 0 & 0 & 0 \\
Obgin & 36 & $6(16,6)$ & $30(83,4)$ & 0 & 0 & 0 \\
Bedah urologi & 2 & $1(50)$ & $1(50)$ & 0 & 0 & 0 \\
Trauma & 18 & $4(22,2)$ & $14(77,8)$ & 0 & 0 & 0 \\
Spinal injuri & 2 & $1(50)$ & $1(50)$ & 0 & 0 & 0 \\
Bedah saraf & 54 & $5(9,2)$ & $49(90,7)$ & 0 & 0 & 0 \\
Total & 274 & $99(36,1)$ & $175(63,9)$ & 10 & 0 & $10(100)$ \\
\hline
\end{tabular}

Keterangan: untuk data disajikan dengan persentase 
Tabel 4 Tingkat Kepatuhan terhadap Pedoman VTE di Rumah Sakit

\begin{tabular}{lccccccccc}
\hline \multirow{2}{*}{$\begin{array}{c}\text { Klasifikasi } \\
\text { Pasien }\end{array}$} & Total Pasien & $\begin{array}{c}\text { Profilaksis Sesuai } \\
\text { dan Adekuat }\end{array}$ & \multicolumn{2}{c}{$\begin{array}{c}\text { Profilaksis } \\
\text { Tidak Sesuai }\end{array}$} & $\begin{array}{c}\text { Profilaksis } \\
\text { Tidak Adekuat }\end{array}$ & \multicolumn{2}{c}{$\begin{array}{c}\text { Tanpa } \\
\text { Profilaksis }\end{array}$} \\
\cline { 2 - 10 } & $\mathbf{n}$ & $\mathbf{n}$ & $\mathbf{\%}$ & $\mathbf{n}$ & $\mathbf{\%}$ & $\mathbf{n}$ & $\mathbf{\%}$ & $\mathbf{n}$ & $\mathbf{\%}$ \\
\hline Nonbedah & 57 & 31 & 54,4 & 0 & 0 & 3 & 5,5 & 23 & 40,1 \\
Bedah ortopedi & 6 & 0 & 0 & 2 & 33,3 & 1 & 16,7 & 3 & 50 \\
Bedah umum & 99 & 22 & 22,2 & 0 & 0 & 23 & 23,2 & 54 & 54,6 \\
Obgin & 36 & 3 & 8,3 & 0 & 0 & 3 & 8,3 & 30 & 83,4 \\
Bedah urologi & 2 & 1 & 50 & 0 & 0 & 0 & 0 & 1 & 50 \\
Trauma & 18 & 1 & 5,5 & 3 & 16,7 & 0 & 0 & 14 & 77,8 \\
Spinal injuri & 2 & 0 & 0 & 1 & 50 & 0 & 0 & 1 & 50 \\
Bedah saraf & 54 & 1 & 1,9 & 0 & 0 & 4 & 7,4 & 49 & 90,7 \\
Total & 274 & 59 & 21,5 & 6 & 2,2 & 34 & 12,4 & 175 & 63,9 \\
\hline
\end{tabular}

Keterangan: data kategorik disajikan dengan jumlah dan persentase

Pada penelitian ini didapatkan usia terbanyak adalah 46-55 tahun dan 56-64 tahun, yaitu masing-masing sebanyak $21,8 \%$. Pasien dengan usia $\geq 46$ tahun yang menjalani perawatan di ruang intensif meningkatkan risiko VTE dikarenakan faktor yang menambah risiko VTE salah satunya adalah usia tua. Risiko VTE akan meningkat 1,7-1,9 kali setiap dekade. Insidensi VTE pascaoperasi akan meningkat pada pasien usia $\geq 65$ tahun. ${ }^{11}$ Pasien usia $\geq 46$ tahun yang menjalani perawatan di ruang intensif meningkatkan risiko VTE dikarenakan faktor yang menambah risiko VTE salah satunya adalah usia tua. Risiko VTE akan meningkat 1,7-1,9 kali setiap dekade.
Insidensi VTE pascaoperasi akan meningkat pada pasien usia $\geq 65$ tahun. ${ }^{13}$

Banyak faktor yang meningkatkan risiko trombosis pada lansia seperti imobilitas, keganasan, peningkatan level faktor koagulasi, dan penyakit peyerta lainnya. Lebih lanjut, faktor-faktor risiko genetik yang umum, misalnya mutasi faktor $\mathrm{V}$ Leiden dan juga protrombin 20210A juga dikaitkan dengan risiko trombotik pada lansia, meskipun risiko relatif lebih rendah dibanding dengan populasi yang lebih muda. Penelitian menemukan bahwa imobilisasi berkontribusi lebih dari $40 \%$ untuk semua kejadian trombotik vena dan faktor genetik menjelaskan antara $7 \%$ dan

Tabel 5 Pemberian profilaksis VTE yang Tidak Sesuai

\begin{tabular}{lccc}
\hline \multicolumn{1}{c}{ Karakteritik } & Total Pasien & $\boldsymbol{\Sigma}$ Tidak Sesuai & $\%$ \\
\hline Nonbedah & 57 & 0 & 0 \\
Ortopedi & 6 & 2 & 33,3 \\
Bedah umum & 99 & 0 & 0 \\
Obgin & 36 & 0 & 0 \\
Urologi & 2 & 0 & 0 \\
Trauma & 18 & 3 & 16,7 \\
SCI & 2 & 1 & 50 \\
Bedah saraf & 54 & 0 & 0 \\
Total & 274 & 6 & 2,2 \\
\hline
\end{tabular}

Keterangan: data kategorik disajikan dengan bentuk jumlah dan persentase 
Tabel 6 Penyebab Pemberian Profilaksis VTE yang Tidak Adekuat

\begin{tabular}{|c|c|c|c|c|c|c|c|c|c|}
\hline \multirow[t]{2}{*}{$\begin{array}{l}\text { Klasifikasi } \\
\text { pasien }\end{array}$} & \multirow[t]{2}{*}{ n } & \multicolumn{2}{|c|}{$\begin{array}{l}\text { Mulai } \\
\text { Pemberian } \\
\text { Terlambat }\end{array}$} & \multicolumn{2}{|c|}{$\begin{array}{c}\text { Mulai Pemberian } \\
\text { Terlambat dan } \\
\text { Penghentian Terlalu } \\
\text { Cepat }\end{array}$} & \multicolumn{2}{|c|}{$\begin{array}{c}\text { Waktu } \\
\text { Penghentian } \\
\text { Terlalu Cepat }\end{array}$} & \multicolumn{2}{|c|}{$\begin{array}{c}\text { Dosis Obat } \\
\text { Tidak } \\
\text { Adekuat }\end{array}$} \\
\hline & & f & $\%$ & f & $\%$ & $\mathbf{F}$ & $\%$ & f & $\%$ \\
\hline Nonbedah & 3 & 1 & 33,3 & 0 & 0 & 0 & 0 & 2 & 66,7 \\
\hline Bedah ortopedi & 1 & 1 & 100 & 0 & 0 & 0 & 0 & 0 & 0 \\
\hline Bedah umum & 23 & 11 & 47,8 & 0 & 0 & 0 & 0 & 12 & 52,2 \\
\hline Obgin & 3 & 1 & 33,3 & 0 & 0 & 0 & 0 & 2 & 66,7 \\
\hline Bedah urologi & 0 & 0 & 0 & 0 & 0 & 0 & 0 & 0 & 0 \\
\hline Trauma & 0 & 0 & 0 & 0 & 0 & 0 & 0 & 0 & 0 \\
\hline Spinal injuri & 0 & 0 & 0 & 0 & 0 & 0 & 0 & 0 & 0 \\
\hline Bedah saraf & 4 & 4 & 100 & 0 & 0 & 0 & 0 & 0 & 0 \\
\hline Total & 34 & 18 & 52,9 & 0 & 0 & 0 & 0 & 16 & 47,1 \\
\hline
\end{tabular}

Keteragan: untuk data kategorik disajikan dengan jumlah dan persentase

$22 \%$ dari kejadian trombotik. ${ }^{14}$

Wanita usia subur mempunyai risiko tambahan untuk VTE seperti kontrasepsi oral, terapi hormon, kehamilan dan puerperium, dan terapi modulator reseptor estrogen selektif (raloxifene). ${ }^{11}$ Pada penelitian ini ditemukan sebanyak 79,9\% pasien yang dirawat di ICU RSHS mempunyai risiko tinggi VTE, 16,6\% pasien dengan risiko sedang terjadi VTE sehingga harus mendapatkan profilaksis VTE dan 3,5\% pasien mempunyai risiko rendah yang tidak membutuhkan profilaksis VTE. Hal ini disebabkan oleh hampir semua pasien kritis yang dirawat di ICU memiliki beberapa faktor risiko yang meningkatkan risiko VTE. Faktor risiko yang sering didapatkan adalah usia tua, jenis operasi besar, tumor, hamil, imobilisasi lama, trauma, spinal cord injury, strok, sepsis, gagal napas, gagal jantung, ventilasi mekanik, central venous catheter (CVC) dan gagal ginjal. ${ }^{7}$

Secara keseluruhan pasien yang menjalani perawatan di ruang intensif di Rumah Sakit Dr. Hasan Sadikin Bandung periode Januari-Desember 2016 yang mempunyai indikasi untuk pemberian tromboprofilaksis sebesar 96,5\% (Tabel 2), tetapi pasien yang mendapatkan profilaksis VTE hanya 36,1\% dari pasien yang memiliki indikasi pemberian tromboprofilaksis (Tabel 3) dan pasien yang mendapatkan profilaksis sesuai dan adekuat berdasar pedoman ACCP, yaitu sebanyak $21,5 \%$ (Tabel 4). Hasil penelitian ini lebih rendah daripada penelitian sebelumnya dengan angka kepatuhan rerata terhadap pedoman adalah $59 \%$ untuk pasien bedah dan $40 \%$ untuk pasien nonbedah. ${ }^{5} \mathrm{Hal}$ ini menunjukkan bahwa pasien yang dirawat di ICU sangat berisiko terjadi VTE. Dari sejumlah penelitian menunjukkan bahwa angka kejadian VTE akan berkurang dengan pemberian tromboprofilaksis tepat dan sesuai.

Pada penelitian ini menemukan pasien yang menjalani perawatan di ICU RSHS tidak sesuai diberikan profilaksis VTE sebanyak 2,2\%. Pada penelitian ini ketidaksesuaian tromboprofilaksis disebabkan oleh pasien yang mempunyai indikasi untuk diberikan LMWH, tetapi mendapatkan LDUH atau pasien yang menurut pedoman ACCP mendapatkan profilaksis kombinasi LMWH dengan profilaksis mekanik, tetapi mendapatkan LDUH. Hal ini mungkin disebabkan oleh harga LMWH lebih mahal dan alat profilaksis mekanis tidak mencukupi di ICU RSHS.

Pemberian tromboprofilaksis yang tidak sesuai pada penelitian ini ditemukan pada 
pasien ortopedi, trauma, dan spinal injuri. Berdasar pedoman ACCP, tromboprofilaksis yang diberikan pada pasien ortopedi risiko tinggi adalah LMWH, sedangkan pada penelitian ini diberikan LDUH. Pada pasien trauma dan spinal injury seharusnya diberikan tromboprofilaksis LDUH atau LMWH dikombinasikan dengan profilaksis mekanik, namun pada penelitian ini hanya diberikan LDUH. ${ }^{15}$

Pemberian LMWH tersebut adalah sebagai tromboprofilaksis VTE sangat efektif dan aman pada pasien ortopedi dibanding dengan LDUH. Hal ini disebabkan oleh LMWH mempunyai komplikasi perdarahan lebih kecil dibanding dengan LDUH. ${ }^{15}$ Berat molekul LMWH sekitar sepertiga dari UFH. LMWH memiliki berat molekul rerata 4.000 hingga 5.000 yang setara dengan sekitar 15 unit sakarida dan kisaran 2.000 hingga $9.000 .^{16}$

The American College of Chest Physicians merekomendasikan tromboprofilaksis pasien dengan SCI akut menggunakan kombinasi tromboprofilaksis mekanik dan farmakologi (LDUH atau LMWH + IPC atau GCS) untuk perlindungan yang lebih besar terhadap VTE. Pasien SCI dihubungkan dengan beberapa faktor risiko yang meningkatkan risiko VTE meliputi paraplegia atau tetraplegia, klasifikasi cedera spinal, patah tulang ekstremitas bawah yang bersamaan yang menyebabkan pasien tirah baring lama mengakibatkan stasis vena meningkat. Penambahan tromboprofilaksis mekanik akan meningkatkan efek pencegahan terhadap kejadian VTE dengan mekanisme menurunkan stasis vena. ${ }^{17}$

Low dose unfractionated heparin pada pasien trauma tidak direkomendasikan sebagai tromboprofilaksis tunggal. Sebuah metaanalisis telah memperlihatkan bahwa LDUH tidak lebih efektif dibanding tanpa tromboprofilaksis (OR, 0,97; IK 95\%, 0,352,64). Sebuah penelitian membandingkan LDUH dengan LMWH yang diberikan 36 jam setelah cedera terhadap 344 pasien trauma mayor tanpa perdarahan intrakranial atau perdarahan di tempat lain menemukan bahwa LMWH lebih efektif daripada LDUH. Pada pasien yang diberikan LMWH risiko perdarahanya, yaitu sebesar $<2 \%$ dan sisanya tidak ada perbedaan yang signifikan dalam tingkat perdarahan, transfusi darah, atau perubahan hematokrit. Studi lain secara acak terhadap 486 pasien trauma mayor yang diberikan tromboprofilaksis LMWH atau IPC didapatkan sebanyak 3\% kelompok IPC dan $1 \%$ pada pasien yang menerima LMWH terdeteksi DVT atau PE. Risiko perdarahan mayor pada kedua kelompok tersebut adalah $<2 \%$, penelitian ini menunjukkan bahwa tidak ada kontraindikasi LMWH pada pasien trauma. Sebuah penelitian pada 227 pasien trauma atau ortopedi menemukan bahwa LDUH yang dikombinasikan dengan tromboprofilaksis mekanik lebih efektif daripada LDUH saja. Pada penelitian ini menemukan tingkat DVT pada kelompok LDUH lebih tinggi dibanding dengan kelompok kombinasi tromboprofilaksis, yaitu masing-masing 22\% dan $3 \%(p<0,001) \cdot{ }^{17}$ Peran tromboprofilaksis mekanik dalam pencegahan VTE adalah meningkatkan aliran darah vena dengan penekanan mekanik sehingga meningkatkan efektivitas tromboprofilaksis VTE bila dikombinasikan dengan tromboprofilaksis secara farmakologis. ${ }^{18,19}$

Untuk memahami alasan pemberian tromboprofilaksis yang tidak adekuat, peneliti memeriksa faktor-faktor termasuk waktu awal pemberian dan penghentian tromboprofilaksis, durasi pemberian yang tidak memadai dan dosis profilaksis yang tidak adekuat. Penelitian ini menemukan pemberian profilaksis yang tidak adekuat dikarenakan keterlambatan pemberian tromboprofilaksis sebanyak 52,9\% dan dosis yang tidak adekuat, yaitu 47,1\%. Presentase terbesar pada pasien yang terlambat diberikan tromboprofilaksis, yaitu pasien ortopedi dan bedah saraf sebanyak 100\% dan presentase terbesar Presentase terbesar pasien yang diberikan tromboprofilaksis dengan dosis yang tidak adekuat, yaitu pasien nonbedah dan obgin sebanyak $66,7 \%$. Hasil penelitian ini berbeda dengan penelitian sebelumnya yang menemukan alasan pemberian tromboprofilaksis yang tidak adekuat adalah waktu pemberian terlambat dan penghentian 
yang terlalu cepat. ${ }^{6}$ Penyebab pemberian tromboprofilaksis yang tidak adekuat kemungkinan disebabkan oleh persepsi bahwa VTE bukan masalah klinis yang signifikan, kekhawatiran tentang risiko perdarahan ${ }^{20}$ dan kurang kepercayaan pada efektivitas terapi antitrombotik. Pemberian tromboprofilaksis yang tidak adekuat dapat menyebabkan tromboprofilaksis juga tidak efektif sehingga tujuan pemberian tidak tercapai, hal tersebut secara tidak langsung dapat memperpanjang masa perawatan dan meningkatkan angka morbiditas serta mortalitas. ${ }^{6}$

\section{Simpulan}

Berdasar hasil penelitian dan pembahasan dapat dirumuskan beberapa simpulan sebagai berikut: angka kepatuhan pemberian profilaksis VTE berdasar pedoman ACCP di ICU RSUP Dr. Hasan Sadikin Bandung periode Januari-Desember 2016 masih rendah. Proporsi pasien yang menerima profilaksis VTE hanya sepertiga pasien yang memiliki indikasi diberikan profilaksis VTE. Pemberian profilaksis VTE tidak adekuat di ICU RSUP Dr. Hasan Sadikin Bandung periode Januari-Desember 2016 ditemukan sebanyak seperdelapan yang disebabkan oleh sebagian besar pemberian yang terlambat. Pemberian profilaksis VTE tidak sesuai di ICU RSUP Dr. Hasan Sadikin Bandung periode JanuariDesember 2016 ditemukan sebanyak 2,2\%.

\section{Daftar Pustaka}

1. Adriance SM, Murphy CV. Prophylaxis and treatment of venous thromboembolism in critically ill. Int J Crit Illn Inj Sci. 2013;3:143-51.

2. Moser KM. Venous thromboembolism. Dalam: Kluwer W, penyunting. Marino's Edisi ke-4. The ICU Book. Philadelphia: Lippincott Williams \& Wilkins. 2014. Hlm. 97-105.

3. Kaushansky, K, Lichtman MA, Beutler E, Kipps TJ, Seligsohn U, Prchal JT. Venous thrombosis. Dalam: Raskob GE, Hull RD; Pineo GF, penyunting. Williams hematology. Edisi ke-8. China: The
McGraw-Hill Companies, Inc.P; 2010. hlm. 2700-20.

4. Boodi M, Peris A. Deep vein thrombosis on intensive care. Adv Exp Med Biol. Switzerland. 2015;2:167-81.

5. Hutajulu SV. Thromboembolism prophylatic. Dalam: Pangalila FJV, Mansjoer A, penyunting. Penatalaksanaan sepsis dan syok septik (optimalisasi Fashugbid). Jakarta: Perdici; 2017. hlm. 28-32.

6. Ting Y, Dylan M, Lin J, Dubois R. Hospitals' compliance with prophylaxis guidelines for venous thromboembolism. Am I Health-Syst Pharm. 2007;24:69-74.

7. Minet C, Potton L, Bonadona A, Roy RH, Somohano CA, Lugosi M, dkk. Venous thromboembolism in the ICU: main characteristics, diagnosis and thromboprophylaxis. BioMed Central. Crit Care. 2015;19:287.

8. Cohen AT, Tapson VF, Bergmann JF, Goldhaber SZ, Kakkar AK, Deslandes B, dkk. Venous thromboembolism risk and prophylaxis in the acute hospital care setting (ENDORSE study): a multinational cross-sectional study. Lancet. 2008;371:387-93.

9. Essam AE, Sharif G, Al Hameed F. Venous thromboembolism related mortality and morbidity in King Fahd General Hospital, Jeddah, Kingdom of Saudi Arabia. Ann Thorac Med. 2011;6:193-8.

10. Bauer KA, Lip GYH. Overview of the causes of venous thrombosis. UpToDate. 2004;12:166.

11. Heraudeau A, Delluc A, Henaff ML, Lacut K, Leroyer C, Desreus B, dkk. Risk of venous thromboembolism in association with factor V leiden in cancer patient. Plos one. Barcelona. 2018;13:5.

12. Guyatt GH, Aki EA, Crowther M, Agnelli G, Bolis G, Capussotti;s L, dkk. Executive summary: antithrombotic therapy and prevention of thrombosis. American College of Chest Physicians EvidenceBased Clinical Practice Guidelines. Chest. 2012;141(Suppl):7-47S.

13. Heit JA, Spencer FA, White RH. The epidemiology ofvenous thromboembolism. 
J Thromb Thrombolysis. 2016;41:3-14.

14. Engbers MJ, Vlieg VH, Rosendaal FR. Venous thrombosis in elderly: incidence, risk and risk groups. J Thromb Haemost. 2010;8:2105-12.

15. Geerts WH, Bergqvist D, Pineo GF, Enoch S, Woon E. Prevention of venous thromboembolism. American College of Chest Physicians Evidence-Based Clinical Practice Guidelines. Chest. 2008;133(Suppl):381-453S.

16. King CS, Holley AB, Jackson JL, Nordstrom M, Lindblad B, Bergqvist D. Twice vs. three times daily heparin dosing for thromboembolism prophylaxis in the general medical population. a metaanalysis. Chest 2007;131:507-16.

17. Consortium for Spinal Cord Medicine. Prevention of venous thromboembolism in individual with spinal cord injury: clinical practice guidelines for health care provider. Top Spinal Cord Inj Rehabil. 2016;22(3):209-240.

18. Imberti D, Ageno W. A survey of thromboprophylaxis management in patients with major trauma. Pathophysiol Haemost Thromb. 2005;34:249-54.

19. Garcia DA, Baglin TP, Weitz JI, Samama MM. Parenteral anticoagulants. Antithrombotic therapy and prevention of thrombosis. American College of Chest Physicians EvidenceBased Clinical Practice Guidelines. Chest. 2012;141(Suppl):24-43S.

20. Manoucheri R, Fallahi MJ. Adherence to venous thromboprophylaxis guidelines for medical and surgical inpatients of teaching hospital, Shiraz-Iran. National Institute of tuberculosis and lung disease. Iran: Tanaffos. 2015;14:17-26. 